\title{
The Silicon Valley Model
}

\section{Dear Reader,}

Silicon Valley in California has become synonymous with a culture of technological innovation and entrepreneurship. It is a place where a wide range of hightech products are designed, products that go well beyond the computer chips and transistors produced with the semiconducting material referred to in its name products such as automobiles. Other IT clusters have been eager to adopt the terms "silicon" and "valley" when referring to themselves in the hopes of establishing an association with the original Silicon Valley. We now have the "Silicon Alps", a tech hub in Carinthia, Austria, the Munich-based "Isar Valley" and, of course, the other Silicon Valley in Bangalore, India.

The IT cluster known as Rhein-MainNeckar, a region that includes the cities of Frankfurt, Darmstadt, Mannheim, Karlsruhe and Heidelberg, is plausibly referred to as the Silicon Valley of Europe because of its predominant software industry. Among insiders, the university city of Bochum is a Silicon Valley mecca for young and talented security engineers, many of whom are recruited to the original Silicon Valley - another successful German export.

Still, the original Silicon Valley continues to attract ever more German companies, and not only major companies like Daimler, Deutsche Telekom and Siemens. Many small and medium-sized enterprises and consulting firms are setting up offices in Silicon Valley, far more than in other states in the United States, to be close to start-up companies and future customers.

The number and diversity of potential partnerships, however, is apparently not the only reason. Many German executives who have spent time in Silicon Valley speak of an entrepreneurial spirit, an enthusiastic pragmatism and a willing- ness to embrace the ventures of others that have no counterpart in Germany although the rest of the world often associates these qualities with German industry. And, of course, there is mention of the courage to face and accept the risk of failure, which is something to be taken in stride on the way to success. How contrary to the zero-mistakes culture emphasised by Volkswagen's exCEO Dr. Martin Winterkorn.

Many of these executives have studied at the University of Stanford. One was also on the supervisory board of a startup company. When asked what would be worth emulating in the context of vehicle development back at home in Germany, he showed a certain perplexity and insisted that the systems and business cultures were simply too different. This would be regrettable because the key to future success is greater openness, flexibility and integrative capacity.

Many of you may not share this opinion and hasten to point out your many years of "intercultural” experience. This could make for an exciting discussion as the automobile industry continues to face the challenge of having to reinvent itself.
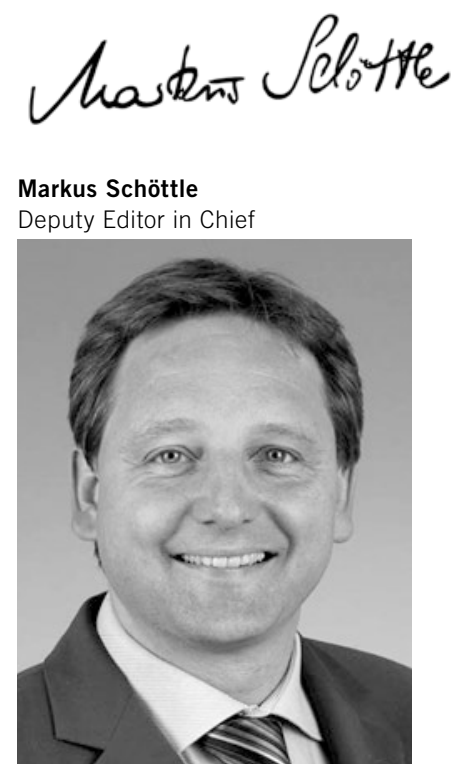